\title{
Principais Enterites Parasitárias em Cães: Revisão
}

\author{
Parasitary Enterites in Dogs: Review
}

\begin{abstract}
Angélica Cristina Ferreira Prado ${ }^{\mathrm{a}}$; Elaine Santana Gonçalves ${ }^{\mathrm{b}}$; Michelli Pereira ${ }^{\mathrm{b}}$; Sávio Tadeu Almeida Júnior ${ }^{\mathrm{a}}$; Elizângela Guedes*ab
\end{abstract}

\begin{abstract}
${ }^{a}$ Universitário do Sul de Minas, curso de Medicina Veterinária. MG, Brasil.
bUniversidade José do Rosário Vellano, Programa de Pós-Graduação Stricto Sensu em Reprodução, Sanidade e Bem-Estar Animal. MG, Brasil.

*E-mail: elizangela.guedes@unifenas.br
\end{abstract}

\begin{abstract}
Resumo
As enterites parasitárias são consideradas as principais causas de transtornos intestinais em cães domésticos (Canis familiaris), desempenhando um papel importante na saúde animal e saúde pública. Ancylostoma caninum, Toxocara canis. Giardia spp. Cryptosporidium spp. e Cystoisospora spp são os enteroparasitas descritos com maior frequência na rotina clínica. Considerando a importância da infecção por esses agentes em cães, o presente trabalho realizou uma revisão bibliográfica sobre os principais parasitas entéricos que acometem os cães, objetivando compreender seus aspectos biológicos, patogênicos, de diagnóstico, tratamento e sua profilaxia. O conhecimento do ciclo biológico e as formas de transmissão de cada parasito é imprescindível para compreender suas formas de disseminação, as técnicas diagnósticas apropriadas e a prevenção das enfermidades. O estreito convívio entre animais e o homem, principalmente no que se refere aos animais de companhia, vem propiciando o surgimento e ressurgimento de potenciais zoonoses. Dessa forma, o conceito de One Health deve estar, a cada dia, mais inserido na sociedade e principalmente entre os médicos veterinários.
\end{abstract}

Palavras-chave: Giardia. Caninos. Zoonose. Toxocara canis. Vermifugação.

\begin{abstract}
Parasitic enteritis is considered the main cause of intestinal disorders in domestic dogs (Canis familiaris), playing an important role in animal health and public health. Ancylostoma caninum, Toxocara canis. Giardia spp. Cryptosporidium spp. and Cystoisospora spp. are the most frequently described enteroparasites in clinical routine. Considering the importance of infection by these agents in dogs, the present work carried out a literature review on the main enteric parasites that affect dogs, aiming to understand their biological, pathogenic, diagnostic, treatment and prophylaxis aspects. Knowledge of the biological cycle and forms of transmission of each parasite is essential to understand its forms of dissemination, appropriate diagnostic techniques and disease prevention. The close relationship between animals and man, especially with regard to companion animals, has led to the emergence and resurgence of potential zoonosis. Thus, the concept of One Health must be, every day, more inserted in society and especially among veterinarians.
\end{abstract}

Keywords: Giardia. Canines. Zoonosis. Toxocara canis. Deworming.

\section{Introdução}

O aumento da população canina e a estreita relação com o homem tornou-se algo extremamente relevante para a saúde pública, devido ao potencial zoonótico de várias parasitoses (CAPUANO; ROCHA, 2006; VASCONCELOS; BARROS; OLIVEIRA 2006). Os cães são parasitados por espécies de trematódeos, cestódeos, nematódeos e um grande número de protozoários (FUNADA et al., 2007; PINTO FERREIRA et al., 2013; VASCONCELLOS; BARROS; OLIVEIRA, 2006).

As enterites parasitárias são consideradas uma das principais causas de transtornos intestinais em cães, interferindo negativamente no desenvolvimento e exercendo um papel importante como espoliadores de nutrientes (ALVES; GOMES; SILVA, 2005; FERREIRA et al., 2010). Comumente ocorrem em animais jovens, errantes e aqueles densamente abrigados, onde o tipo de manejo, principalmente por maior contato com água e alimentos contaminados, e fezes de animais infectados (KATAGIRI; OLIVEIRA-SEQUEIRA, 2007).

Os cães parasitados podem apresentar sintomatologia como apatia, diminuição da performance, perda de peso, vômitos e diarreia (FERREIRA et al., 2010). No entanto, alguns animais podem ser assintomáticos e, ainda, portadores, constituindo um importante agente na contaminação do ambiente e o estabelecimento de novos casos (SILVA et al., 2017).

Pesquisas sobre a prevalência de enteroparasitas têm sido realizadas no Brasil com resultados variando de $8 \%$ até $86 \%$ sendo as espécies Ancylostoma caninum, Toxocara canis. Giardia spp. Cryptosporidium spp. Cystoisospora spp comumente reportadas (FUNADA et al., 2007; PINTO FERREIRA et al., 2013; VASCONCELLOS; BARROS; OLIVEIRA, 2006).

Considerando a importância dos enteroparasitas em cães, tanto no aspecto da clínica veterinária como da saúde pública, 
buscamos realizar uma revisão bibliográfica sobre o tema a fim de discorrer sobre as espécies de maior ocorrência, o diagnóstico bem como as medidas de controle e profilaxia das principais enteroparasitoses caninas.

\section{Desenvolvimento}

\subsection{Metodologia}

Foi realizada uma revisão de literatura narrativa, elaborada por meio de pesquisa bibliográfica a fim de discorrer sobre as principais espécies de endoparasitas caninos, abordando o diagnóstico e as medidas de controle. Foram utilizados os buscadores Elsevier, Google Academic, Periódicos Capes, Science Direct e Medline e os seguintes descritores: cães, parasitismo, endoparasitas, enteropatias, Giardia spp., giárdia, protozoários, isosporose canina, verminose canina. Também foram selecionados livros. Para a seleção foram utilizados como critérios de inclusão estudos publicados entre 2000 a 2021, tanto em Língua Inglesa como Portuguesa, e a relevância para a temática. Foram excluídos trabalhos sem embasamento científico ou aqueles cujos dados não tenham sido disponibilizados por completo.

\subsection{Giardíase}

A giardíase é uma doença causada pela Giardia sp., um protozoário flagelado que acomete vários vertebrados como mamíferos, répteis, pássaros e o ser humano. $\mathrm{O}$ gênero Giardia contém várias espécies de protozoários flagelados que são indistinguíveis morfologicamente, e a especificidade do hospedeiro é considerada mínima para Giardia sp. (ADAM, 2001).

Dentre as espécies, G. duodenalis, também conhecida como G. intestinalis ou G. lamblia, é descrita com maior frequência entre caninos (LALLO; BONDAN, 2016). Devido à grande diversidade genômica encontrada nas espécies de $G$. duodenalis suas subespécies foram agrupadas em genótipos, sendo atualmente divididas filogeneticamente em oito genótipos classificados de A a H. Os genótipos A e $\mathrm{B}$ são considerados potencialmente zoonóticos, infectando humanos e uma grande variedade de mamíferos, enquanto os genótipos $\mathrm{C}$ a $\mathrm{H}$ são consideradas específico do hospedeiro (BALLWEBER et al., 2010; FANTINATTI et al., 2020; RYAN, 2013).

Este parasito é restrito ao trato gastrintestinal, se instalando frequentemente no duodeno e jejuno, possuindo dois estágios principais no ciclo de vida. A infecção do hospedeiro é iniciada quando o cisto é ingerido com água ou, menos comumente, com alimentos contaminados. Pode ainda ocorrer por contato fecal-oral ou fômites contaminados. Em seguida, após a exposição ao ambiente ácido do estômago, os cistos se transformam em trofozoítos no intestino delgado, com formato piriforme flagelado. No intestino delgado, os trofozoítos se replicam por fissão binária, permanecendo livres no lúmen ou preso à mucosa intestinal, e após a exposição ao fluido biliar, alguns dos trofozoítos podem formar cistos no jejuno e serem eliminados nas fezes, permitindo a conclusão do ciclo de transmissão em um novo hospedeiro (ADAM, 2001; BALLWEBER et al., 2010; LALLO; BONDAN, 2016).

Tanto trofozoítos quanto cistos resistentes podem ser encontrados nas fezes, geralmente dentro de 5 a 7 dias após a infecção, entretanto, a principal forma encontrada nas fezes são os cistos (BALLWEBER et al., 2010).

A fisiopatologia da doença ainda é alvo de pesquisas, entretanto, até o momento estudos apontam como consequência ao parasitismo a ruptura do epitélio intestinal do hospedeiro e da camada mucosa sobrejacente, alteração da microbiota do hospedeiro, perda da função de barreira epitelial e recrutamento de linfócitos CD8 + (LALLO; BONDAN, 2016; KRAFT et al., 2017; MANKO-PRYKHODA et al., 2020).

Por se tratar de um parasito extracelular, os trofozoítos ao colonizar o intestino delgado do hospedeiro, se fixam por meio de seu disco ventral, realocando os nutrientes do hospedeiro (ADAM, 2001; KRAFT et al., 2017). Como consequência, além do sequestro de nutrientes e alterações no metabolismo lipídico do hospedeiro, há dano epitelial, rompimento da camada de muco e disbiose da microbiota intestinal (BURET et al., 2015; KRAFT et al., 2017; MANKO-PRYKHODA et al., 2020).

A giardíase canina geralmente é assintomática, o que facilita a disseminação de cistos no meio ambiente, podendo contaminar o homem e outros animais. A ocorrência de manifestação geralmente está relacionada a animais jovens ou adultos imunossuprimidos (ELIGIO-GARCIA et al., 2008). A manifestação clínica inclui diarreia contínua ou intermitente, de consistência pastosa a aquosa, presença muco e esteatorreia. Pode ainda ser observado desconforto e distensão abdominal, anorexia, vômito, flatulência, letargia, perda de peso e déficits de crescimento (TANGTRONGSUP; SCORZA, 2010; ESCCAP, 2011).

Em humanos, G. duodenalis prejudica o ganho de peso e é responsável por uma variedade de complicações extraintestinais e pós-infecciosas, incluindo síndrome do intestino irritável pós-infeccioso, fadiga crônica, deficiência de crescimento e deficiência cognitiva (BURET et al., 2015).

O exame coproparasitológico é o teste laboratorial mais utilizado para o diagnóstico de Giardia sp. (VIDAL; CATAPANI, 2005; BICA; DILLENBURG; TASCA, 2011). Trofozoítos podem ser visualizados em preparações salinas frescas de fezes líquidas ou em lâminas preparadas com álcool polivinílico (PVA), enquanto os cistos podem ser visualizados microscopicamente utilizando diferentes procedimentos de flotação ou sedimentação (BALLWEBER et al., 2010). Entretanto, devido a eliminação de cistos nas fezes ocorrer de forma intermitente, para a confirmação de um diagnóstico negativo de giardíase em cães é recomendável a análise de pelo menos três amostras de fezes, colhidas a cada 48 horas 
(BARUTZKI et al., 2000; LALLO; BONDAN, 2016).

Com relação às características morfológicas, trofozoítos apresentam formato piriforme a elipsoidal, de simetria bilateral, com 12 a $15 \mu \mathrm{m}$ de comprimento e 5 a $9 \mu \mathrm{m}$ de largura, possuem dois núcleos, oito flagelos e dois axóstilos, além de discos suctórios (ventosas) que mantêm o parasito fixo na mucosa para que se alimente (Figura 1). Os cistos, por sua vez, são ovóides e com quatro núcleos (Figura 2) (TAYLOR; COOP; WALL, 2017a).

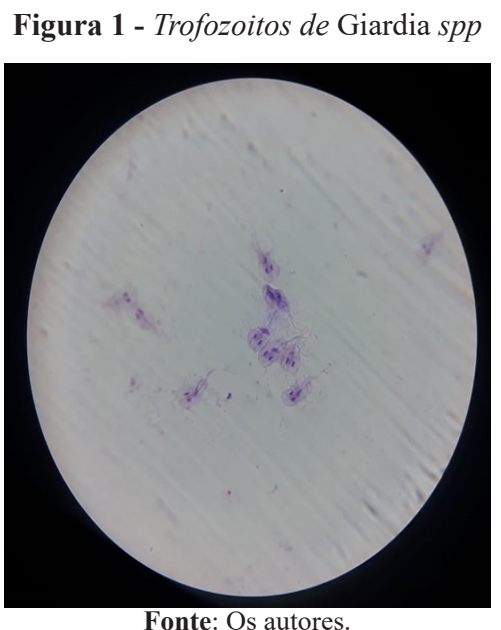

Figura 2 - Cisto de Giardia lamblia

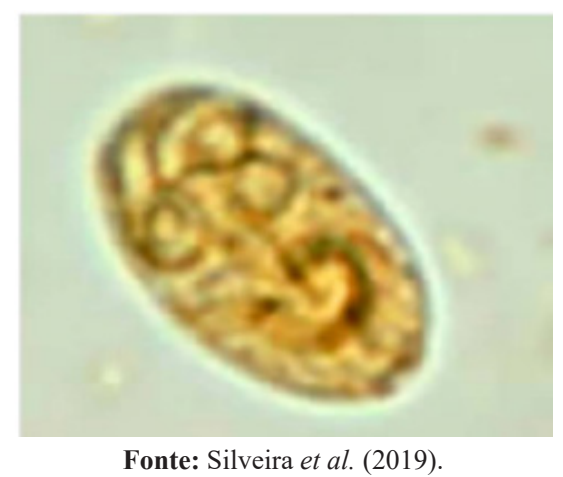

Os métodos de ensaio imunoabsorvente ligado à enzima (ELISA) e ensaio imunocromatográfico comercial visam detectar coproantígenos de Giardia spp. nas fezes (SOUZA et al., 2015; VIDAL; CATAPANI, 2005). Em ambos são utilizados anticorpos monoclonais contra proteínas da parede do cisto e/ou do trofozoíto (GEURDEN et al., 2010). Ainda segundo Geurden et al. (2008), o ensaio imunocromatográfico comercial é um teste específico e bastante sensível para o diagnóstico em cães sintomáticos.

Também podem ser utilizados método sorológico como a imunofluorescência (IFA) (BALLWEBER et al., 2010; GEURDEN et al., 2008), entretanto o resultado não permite distinguir entre uma infecção recente de uma já estabelecida, sendo esta técnica mais utilizada em estudos epidemiológicos (OLSON; BURET, 2001).

As técnicas de biologia molecular tais como a PCR têm como principal vantagem o fornecimento de informações sobre o genótipo, permitindo assim a identificação das diferentes espécies, sendo útil para estudos epidemiológicos e taxonômicos. Embora apresente uma elevada sensibilidade, os inibidores presentes nas amostras fecais podem interferir com as técnicas moleculares (GEURDEN et al., 2010).

As principais drogas descritas em literatura para o tratamento da giardíase canina são apresentadas na Quadro 1.

Quadro 1 - Principais bases farmacológicas utilizadas no tratamento da giardíase canina

\begin{tabular}{|c|c|c|c|}
\hline Base & Dose & $\begin{array}{c}\text { Efeitos } \\
\text { Colaterais }\end{array}$ & Contraindicação \\
\hline Albendazol & $\begin{array}{l}25 \mathrm{mg} / \mathrm{kg} \text {, a } \\
\text { cada } 12 \mathrm{~h} \text {, por } \\
2-10 \text { dias }\end{array}$ & $\begin{array}{l}\text { Dor } \\
\text { abdominal, } \\
\text { prurido, } \\
\text { diarreia, } \\
\text { vômito. }\end{array}$ & $\begin{array}{l}\text { Gestantes, } \\
\text { lactantes, } \\
\text { sensibilidade } \\
\text { benzimidazol }\end{array}$ \\
\hline Febendazol & $\begin{array}{l}50 \mathrm{mg} / \mathrm{kg}, \\
\text { a cada } 24 \\
\text { horas, por } \\
3-5 \text { dias } \\
\end{array}$ & & \\
\hline Mebendazol & $\begin{array}{l}100 \mathrm{mg} / \mathrm{kg}, \\
\text { a cada } 24 \\
\text { horas, por } 3 \\
\text { dias }\end{array}$ & $\begin{array}{l}\text { Náusea, } \\
\text { erupção } \\
\text { cutânea, } \\
\text { diarreia, } \\
\text { vômito }\end{array}$ & $\begin{array}{l}\text { Gestante, } \\
\text { epilepsia, } \\
\text { sensibilidade } \\
\text { benzimidazol }\end{array}$ \\
\hline Metronidazol & $\begin{array}{l}15-65 \mathrm{mg} / \\
\mathrm{kg}, \text { a cada } \\
12 \mathrm{~h} \text {, por } 5 \\
\text { dias }\end{array}$ & $\begin{array}{l}\text { Dor } \\
\text { membros, } \\
\text { prurido, } \\
\text { convulsão, } \\
\text { ação } \\
\text { mutagênica, } \\
\text { diarreia, } \\
\text { vômito }\end{array}$ & $\begin{array}{l}\text { Epilepsia, } \\
\text { cardioparas, } \\
\text { hepatopatas e } \\
\text { gestantes }\end{array}$ \\
\hline Tinidazol & $\begin{array}{l}44 \mathrm{mg} / \mathrm{kg} \text {, a } \\
\text { cada } 24 \mathrm{~h} \text {, por } \\
3 \text { dias }\end{array}$ & $\begin{array}{l}\text { Nausea, } \\
\text { anorexia, } \\
\text { cefaleia, } \\
\text { fadiga, } \\
\text { leucopenia }\end{array}$ & $\begin{array}{l}\text { Gestantes, } \\
\text { lactantes }\end{array}$ \\
\hline Furazolidona & $\begin{array}{l}4 \mathrm{mg} / \mathrm{kg}, \\
\text { a cada } 12 \\
\text { horas, por } 5 \\
\text { dias }\end{array}$ & $\begin{array}{l}\text { Nausea, } \\
\text { vomito, } \\
\text { hipersen- } \\
\text { sibilidade, } \\
\text { prurido } \\
\end{array}$ & $\begin{array}{l}\text { Hipersibilidade, } \\
\text { filhotes com } \\
\text { menos de } 30 \text { dias }\end{array}$ \\
\hline Quinacrina & $\begin{array}{l}6,6 \mathrm{mg} / \mathrm{kg}, \\
\text { a cada } 12 \\
\text { horas, por } 5 \\
\text { dias }\end{array}$ & $\begin{array}{l}\text { Vomito, } \\
\text { anorexia, } \\
\text { diarreia, } \\
\text { hipertermia }\end{array}$ & gestantes \\
\hline
\end{tabular}

Fonte: Fortes (2004); Lallo e Bondan (2016); Lallo, Rodrigues e Bondan (2003).

Estudo conduzido por Moron-Soto et al. (2017) sugere a nitazoxanide na dose de $75-150 \mathrm{mg} / \mathrm{kg}$ como eficaz no tratamento para giardíase em cães, sem maiores efeitos colaterais e pela eliminação de cistos com uma única administração, sendo, inclusive, uma terapêutica vantajosa para cães de canil e abrigos. Já a composição anti-helmíntica mais empregada no controle de helmintos gastrintestinais em cães é constituída de praziquantel, pamoato de pirantel e febantel (Quadro 2). Este último é um antihelmíntico pro-benzimidazol, ou seja, quando ingerido pelo animal é metabolizado em fembendazol, por isso, dentre os outros compostos presentes, sugere-se que possa ter ação giardicida 
(GENNARI; SOUZA 2003).

Quadro 2 - Principais anti-helmínticos comumente utilizados contra parasitos gastrintestinais primários de cães

\begin{tabular}{|c|c|c|c|}
\hline $\begin{array}{c}\text { Anti- } \\
\text { helmíntico }\end{array}$ & Via & Dose & Ação \\
\hline $\begin{array}{l}\text { Pamoato de } \\
\text { pirantel }\end{array}$ & Oral & $5 \mathrm{mg} / \mathrm{kg}$ & $\begin{array}{l}\text { Ancilóstomo, } \\
\text { nematódeo. }\end{array}$ \\
\hline $\begin{array}{l}\text { Embonato de } \\
\text { pirantel }\end{array}$ & Oral & $14 \mathrm{mg} / \mathrm{kg}$ & $\begin{array}{c}\text { Ancilóstomo, } \\
\text { nematódeo. }\end{array}$ \\
\hline Praziquantel & Oral & $5 \mathrm{mg} / \mathrm{kg}$ & $\begin{array}{c}\text { Cestódeo } \\
\text { (Dipylidium canino) } \\
\text { e nematódeos }\end{array}$ \\
\hline $\begin{array}{c}\text { Pamoato de } \\
\text { pirantel/febantel }\end{array}$ & Oral & $\begin{array}{c}5 \mathrm{mg} / \mathrm{kg} \\
\text { e } 15 \mathrm{mg} / \mathrm{kg}\end{array}$ & $\begin{array}{l}\text { Ancilóstomo, } \\
\text { nematódeo, } \\
\text { Trichuris vulpis, } \\
\text { Giardia spp. }\end{array}$ \\
\hline Emodepsida & Oral & $0,45 \mathrm{mg} / \mathrm{kg}$ & $\begin{array}{l}\text { Ancilóstomo, } \\
\text { nematódeo, } \\
\text { Trichuris vulpis. }\end{array}$ \\
\hline $\begin{array}{c}\text { Embonato de } \\
\text { oxantel }\end{array}$ & Oral & $55 \mathrm{mg} / \mathrm{kg}$ & Trichuris vulpis. \\
\hline Milbemicina & Tópico & $0,5 \mathrm{mg} / \mathrm{kg}$ & $\begin{array}{c}\text { Ancilóstomo, } \\
\text { nematódeo, } \\
\text { Trichuris vulpis. }\end{array}$ \\
\hline Moxidectina & Tópica & $2,5 \mathrm{mg} / \mathrm{kg}$ & $\begin{array}{l}\text { Ancilóstomo, } \\
\text { nematódeo, } \\
\text { Trichuris vulpis. }\end{array}$ \\
\hline Ivermectina & Oral & $0,20 \mathrm{mg} / \mathrm{kg}$ & $\begin{array}{c}\text { Ancilóstomo, } \\
\text { nematódeo, } \\
\text { Trichuris vulpis. }\end{array}$ \\
\hline elamectina & Tópica & $6 \mathrm{mg} / \mathrm{kg}$ & $\begin{array}{c}\text { Ancilóstomo, } \\
\text { nematódeo. }\end{array}$ \\
\hline Fenbendazol & Oral & $\begin{array}{c}50 \mathrm{mg} / \mathrm{kg} \\
\text { por } 3 \text { dias } \\
\text { consecutivos. } \\
\text { Para giárdia, } \\
5 \text { dias } \\
\text { consecutivos. }\end{array}$ & $\begin{array}{l}\text { Ancilóstomo, } \\
\text { nematódeo, } \\
\text { Trichuris vulpis, } \\
\text { Giardia spp. }\end{array}$ \\
\hline Oxibendazol & Oral & $10-20 \mathrm{mg} / \mathrm{kg}$ & $\begin{array}{l}\text { Ancilóstomo, } \\
\text { nematódeo, } \\
\text { Trichuris vulpis.. }\end{array}$ \\
\hline
\end{tabular}

Fonte: TroCCAP (2019).

Entretanto, Bowman (2021) sugere que o tratamento da giardíase canina com as atuais terapêuticas disponíveis não proporciona a cura parasitológica total nem impedem a transmissão a outros animais e pessoas, podendo, inclusive, promover a seleção de genótipos resistentes, impactando a saúde humana e animal. Dessa forma, torna-se importante as medidas sanitárias em relação ao ambiente, higiene do animal e prevenção de contaminação fecal em água e alimentos (PAYNE et al., 2002; FORTES, 2004).

Existe no mercado brasileiro uma vacina comercial inativada, entretanto sua utilização ainda é alvo de discussão, tendo sido, por esse motivo, suspensa sua comercialização em muitos outros países (DAY et al., 2020). Ainda, Anderson et al. (2004) e Lund et al. (2010) não observaram a ocorrência de proteção da infecção por Giardia sp. em cães nem tampouco como tratamento eficaz para infecções assintomáticas.

\subsection{Cistoisosporíase (Isosporose)}

A cistoisosporíase (sin. Isosporose) é causada por protozoários coccídios intracelulares obrigatórios, classificados no filo Apicomplexa, que infectam as células epiteliais do intestino de cães e gatos (ADOLPH, 2020).

É um parasito monoxeno, onde seu ciclo envolve apenas um hospedeiro, tendo início com a ingestão de oocistos esporulados presentes em alimentos ou água contaminados (FORTES, 2004).

Após os oocistos entrarem em contato com as secreções do trato gastrointestinal, são liberados para o lúmen intestinal infectando os enterócitos; em seguida, inicia a etapa de desenvolvimento endógeno, no qual se multiplica repetidas vezes dentro das células, de forma assexuada, originando inúmeros merozoítos, que por sua vez, rompem os enterócitos possibilitando infectar outras células intestinais (FORTES, 2004; RAMOS et al., 2016). A fase sexuada tem início, com a formação dos gametas femininos e masculinos, que de sua união, formam os oocistos não esporulados que serão eliminados com as fezes do animal. No ambiente, a esporulação ocorre em condições adequadas de temperatura, umidade e oxigenação, cerca de 48 a 72 horas após sua eliminação (FORTES, 2004; RAMOS et al., 2016).

As espécies Cryptosporidium. canis, C. neorivolta e do complexo Cystoisospora ohioensis, que compreendem as espécies $C$. ohioensis e $C$. burrowsi, já foram descritas em fezes de cães (JOACHIM et al., 2018; DUBEY, 2019).

Entre estas espécies, os oocistos de $C$. canis são maiores e facilmente distinguidos, enquanto os oocistos de $C$. ohioensis, $C$. neorivolta e $C$. burrowsi são de difíceis diferenciação devido à sobreposição em seus tamanhos. No entanto, com base nos estágios de desenvolvimento endógeno, $C$. ohioensis é distinto de $C$. neorivolta e $C$. burrowsi por estarem aderidos ao epitélio superficial do intestino, enquanto $C$. neorivolta e $C$. burrowsi estão predominantemente na lâmina própria. Já com relação aos estágios endógenos de $C$. neorivolta e $C$. burrowsi e não é possível essa diferenciação (DUBEY, 2019). Com relação à patogenicidade, $C$. canis é considerada mais patogênica, embora as espécies do complexo $C$. ohioensis possam causar doença clínica (JOACHIM et al., 2018).

Cystoisospora sp. penetram diretamente nas células epiteliais da membrana mucosa, onde há o desenvolvimento de lesões extensas com destruição das microvilosidades intestinais. Consequentemente, há redução na absorção e processo inflamatório. As espécies $C$. canis, C. ohioensis e $C$. burrowsi são reportadas como causadoras de diarreia em filhotes (6 meses ou menos) e em cães com imunidade enfraquecida (RAMOS et al., 2016; VATNIKOV et al., 2020).

As manifestações clínicas incluem, além de diarreia aquosa ou com presença de muco, desconforto abdominal, inapetência, vômito, perda de peso e desidratação, podendo também haver o desenvolvimento de manifestações 
neurológicas e respiratórias, decorrentes da invasão em tecidos extra intestinais. Geralmente não é observada a presença de sangue nas fezes, pois as lesões ocorrem na camada mais superficial do epitélio, entretanto nos casos de grande ingestão de oocistos pode estar presente (RAMOS et al., 2016). Segundo Adolph (2020) os sinais clínicos são mais comuns em cães provenientes de ambientes pouco higiênicos ou superlotados.

Contudo, em cães adultos, a diarreia pode estar ausente, a menos que apresentem imunossupressão, com doenças preexistentes do trato gastrointestinal ou coinfecção com outros patógenos como Escherichia coli, Salmonella spp., Clostridium spp., Cryptosporidium parvum, Rotavírus e Coronavírus (ADOLPH, 2020; RODRIGUES; MENEZES, 2003; TESSEROLLI; FAYZANO; AGOTTANI, 2005;). Embora os adultos possam ser assintomáticos, há eliminação de oocistos nas fezes (ADOLPH, 2020).

O diagnóstico é realizado pela detecção de oocistos (Figura 2) em amostras fecais associadas ou não à presença de diarreia. Os oocistos são elípticos a ligeiramente ovoides, com parede lisa e pálida, com tamanho e coloração a depender da espécie (Figura 3). Oocistos esporulados possuem dois esporocistos com quatro esporozoítos cada (Figura 4), já os oocitos imaturos (Figura 5), são de difícil distinção dos oocistos imaturos de Eimeria spp. (TAYLOR; COOP; WALL, 2017a).

Figura 3 - esporulado de Cystoisospora canis (aumento de 40X)

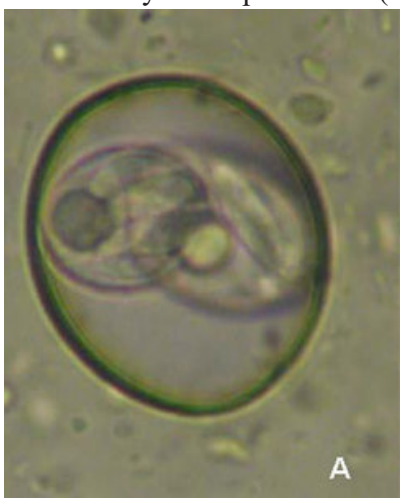

Fonte: Leal et al. (2016).

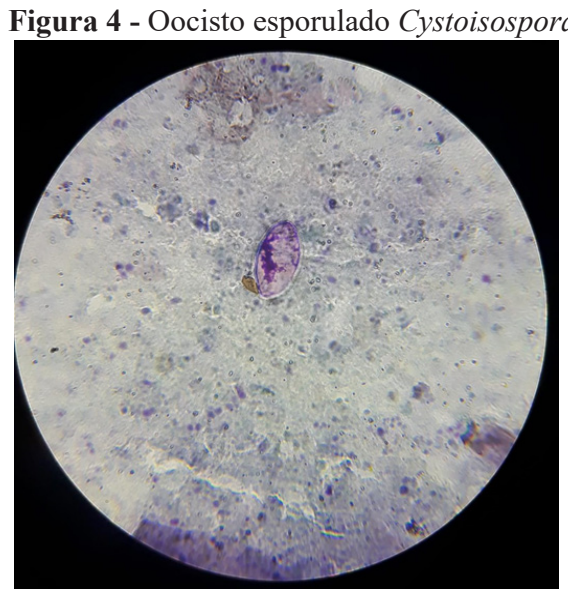

Fonte: Os autores.
Figura 5 - Oocisto não esporulado Cystoisospora spp

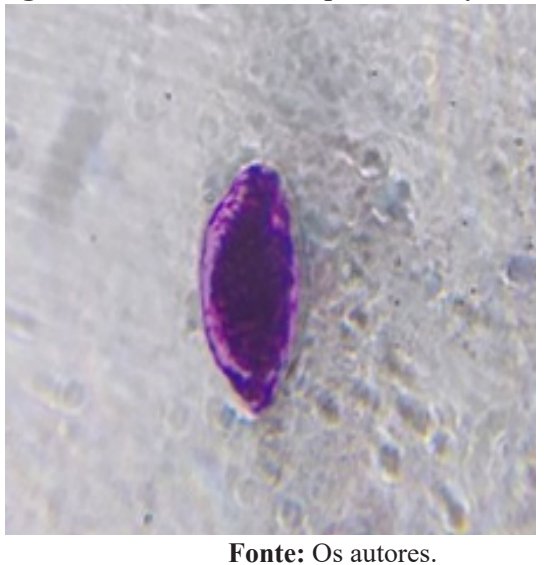

Testes coproparasitológicos como a flotação centrífuga em sulfato de zinco (técnica de Faust) ou uma solução saturada de açúcar, flutuação em cloreto de sódio saturado solução (técnica de Willis-Mollay) podem ser empregados. In vitro, a esporulação seguida de morfometria de oocistos pode ser realizada. Devido ao ciclo, a análise de amostras diarreicas não permite a visualização de oocistos (BRESCIANI; COELHO; PAIVA., 2015).

A coprofagia, comportamento comum em cães, também pode dificultar o diagnóstico, pois a ingestão de fezes de outros animais que não sejam caninos modifica a morfologia do parasita, resultando assim em um diagnóstico coproparasitológico inconclusivo (NIJSSE et al., 2014). Ainda, segundo Joachim et al. (2018), outros testes diagnósticos diferenciais como pesquisa de Giardia devem ser realizados, com o objetivo de avaliar uma possível coinfecção de patógenos entéricos.

Rotineiramente, como tratamento são empregados antibióticos como sulfonamida e trimetoprina (20-30 mg/ $\mathrm{kg}$, via oral, a cada 12 horas, por 15-20 dias), entretanto, essa associação não elimina o coccídeo, mas atua inibindo-o de forma a permitir que as defesas imunológicas do hospedeiro restabeleçam seu controle (NELSON; COUTO, 2015; DOS SANTOS et al., 2019). Já o Conselho Tropical para Parasitos de Animais de Companhia (TROCCAP, 2019) sugere como tratamento sulfadimetoxina (50 mg/kg ao dia por 5-20 dias) ou trimetoprimsulfonamida $(15-30 \mathrm{mg} / \mathrm{kg}$, para animais com até $4 \mathrm{~kg}$, e 30-60 mg/kg, para animais acima de $4 \mathrm{~kg}$, por 6 dias). Alternativamente, pode ser utilizada dose única de toltrazuril $1(0 \mathrm{mg} / \mathrm{kg})$ ou ponazuril $(50 \mathrm{mg} / \mathrm{kg}$ por dia por três dias consecutivos). Na persistência dos sinais clínicos, retratamento deve ser indicado (TROCCAP, 2019).

Também é importante terapia suporte, com reposição de eletrólitos e restabelecimento hídrico, bem como associação de probióticos para auxílio da microbiota intestinal (NELSON; COUTO, 2015; DOS SANTOS et al., 2019). O tratamento de animais imunocomprometidos pode ser muito difícil, sendo necessário medidas de suporte prolongadas (ADOLPH, 2020),

O controle é realizado por meio do isolamento de doentes, 
higienização de bebedouros e comedouros, controle da superpopulação de animais no ambiente, controle da presença de moscas, ratos e baratas (estes podem transmitir oocistos de um ambiente para outro), e desinfecção de ambientes com soluções contendo amônia quaternária (RODRIGUES; MENEZES, 2003; TESSEROLLI; FAYZANO; AGOTTANI, 2005; RAMOS et al., 2016). Ainda, Joachim et al. (2018) recomenda para avaliação da eficácia do tratamento, que amostras fecais sejam coletadas e examinadas semanalmente, de forma individualizada, permitindo assim a identificação correta de animais com potencial liberação ambiental de oocistos.

\subsection{Toxocaríase}

A toxocaríase é uma das zoonoses parasitárias mais prevalentes no mundo, causada principalmente pelo nematóide Toxocara canis, possuindo vários canídeos como hospedeiros definitivos. Os humanos são os hospedeiros paratênicos, se infectanto após a ingestão acidental de ovos embrionados do parasita (MERIGUETI et al., 2017; WAINDOK et al., 2021)

Após a eliminação das fezes com ovos de Toxocara sp. pelos hospedeiros definitivos, há o desenvolvimento da forma infectante (L3) que permanecem no interior do ovo até a ingestão pelo hospedeiro vertebrado (SCHNIEDER; LAABS; WELZ, 2011; WAINDOK et al., 2021). Ao serem ingeridos pelo hospedeiro, os ovos eclodem no duodeno e as larvas infectantes penetram na mucosa do intestino, invadindo os vasos linfáticos e migrando para os linfonodos mesentéricos e posteriormente pelos capilares venosos através da circulação porta, iniciando o ciclo conhecido como hepatotraqueal. A rota de migração subsequente depende de vários fatores, como o estado imunológico e a idade do hospedeiro, bem como o número de larvas ingeridas (MAGNAVAL et al., 2001; SCHNIEDER; LAABS; WELZ, 2011; WAINDOK et al., 2021).

A migração traqueal é a rota predominante em filhotes, mas também pode ocorrer em cães mais velhos em casos de infecção com baixo número de larvas. As larvas penetram nos alvéolos e migram via bronquíolos e traqueia para a faringe; são então engolidas e chegam ao intestino, podendo ser detectadas na traquéia e esôfago 7 a 9 dias após infecção. Em seguida, realiza muda para L4 e atinge o trato gastrointestinal, 7 a 15 dias após a infecção. A última muda para a fase préadulta (L5) ocorre no intestino delgado. Os primeiros ovos são eliminados nas fezes assim que os parasitos adultos amadurecem, aproximadamente 4 a 5 semanas pós-infecção (MAGNAVAL et al., 2001; SCHNIEDER; LAABS; WELZ, 2011; WAINDOK et al., 2021).

Além da migração traqueal, as larvas podem reentrar no sistema circulatório nos pulmões e se distribuir passivamente nos tecidos somáticos, podendo ocorrer o encistamento em uma ampla diversidade de tecidos, inclusive fígado, pulmões, cérebro, coração, músculo esquelético e parede do trato gastrointestinal, no terceiro estádio evolutivo (L3) (SCHNIEDER; LAABS; WELZ, 2011; TAYLOR; COOP; WALL et al., 2017b; WAINDOK et al., 2021).

Nos cães, além da transmissão oral, também pode ocorrer transmissão pela ingestão da L3 em tecidos de hospedeiros paratênicos (como roedores, coelhos, aves, minhocas e caracóis), via transplacentária, via lactogênica, ou ainda pela ingestão de larva L5 pela cadela no momento da higienização das fezes dos filhotes (TAYLOR; COOP; WALL et al., 2017b; CARLIN; TYUNGU, 2020; WAINDOK et al., 2021)

A transmissão transplacentária pode ocorrer após a reativação de larvas somáticas de infecções anteriores da cadela, ou também, a partir de novas infecções durante a gravidez. Dessa forma, no terço final da gestação, as larvas atingem o fígado do feto onde permanecem até o nascimento, para que após o nascimento, continuem a sua migração para os pulmões. As larvas também podem atingir as glândulas mamárias da cadela resultando na transmissão lactogênica (SCHNIEDER; LAABS; WELZ, 2011; WAINDOK et al., 2021).

Estudos têm demonstrado que o pelo dos cães possui a capacidade de abrigar ovos do parasita, representando risco de transmissão para outros animais e para o homem (MERIGUETI et al., 2017). Em humanos, acredita-se que a infecção seja mais comum em crianças, estando mais relacionada ao consumo de alimentos contaminados com ovos de parasitas do que pelo contato direto com animais CARLIN; TYUNGU, 2020; WAINDOK et al., 2021).

A migração larval leva a danos nos tecidos do hospedeiro, justificando a patogenia e sintomatologia da doença. Alguns cães podem apresentar enterite sanguinolenta e em casos graves, pode ocorrer obstruções e rupturas intestinais. Alterações do aparelho respiratório, como a presença de tosse, aumento da frequência respiratória e secreção nasal espumosa, podem ocorrer devido ao seu ciclo extra intestinal. Ainda, podem ser observadas alterações em outros órgãos como fígado, baço e rins. Em filhotes infestados é frequentemente relatado inapetência, diarreia, pneumonia, vômitos com a presença de vermes imaturos, desconforto e distensão abdominal, pelame opaco e retardo no desenvolvimento (FORTES, 2004; SCHNIEDER; LAABS; WELZ, 2011).

No homem, pode ocorrer diferentes manifestações clínicas, sendo algumas mais evidentes como larva migrans visceral ou ocular, e outras mais críticas como neurotoxocaríase, acarretando em atraso neurocognitivo (CARLIN; TYUNGU, 2020; WAINDOK et al., 2021).

O diagnóstico baseia-se na identificação dos ovos (subglobulares e castanhos com casca espessa e rugosa) nas fezes do cão (Figura 6), principalmente pela técnica de flutuação. No entanto, assim como já descrito anteriormente para as outras espécies, uma baixa carga parasitária, a eliminação intermitente de ovos, infecções do mesmo sexo ou formas sexualmente imaturas, e infecções pré-patentes torna o exame coproparaaitológico de rotina menos sensível ou 
até incapaz de detectar parasitas. Dessa forma, a detecção de coproantígeno através de ELISA demonstra-se como técnica complementar ao coproparasitológico (ELSEMORE et al., 2017).

Figura 6 - Ovos de Toxocara canis

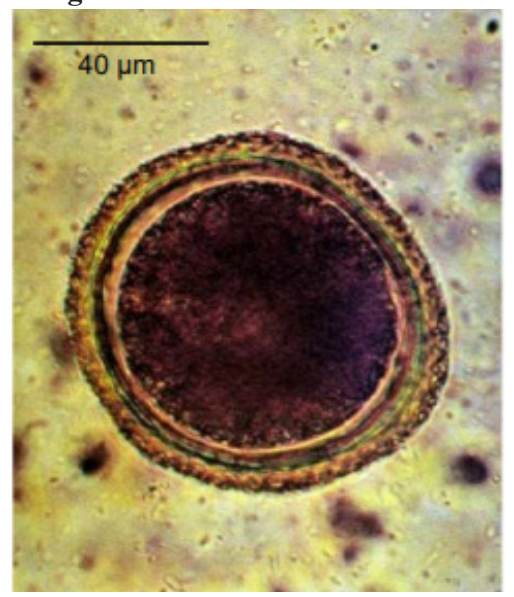

Fonte: Silveira et al. (2019).

Morfologicamente os vermes adultos são grandes, onde as fêmeas medem até $18 \mathrm{~cm}$ e os machos, até $10 \mathrm{~cm}$ de comprimento, de coloração branca/creme, não possuindo interlábio nem ceco. $\mathrm{O}$ adulto de $T$. canis possui cabeça elíptica detentora de um par de grandes asas cervicais lanceoladas (Figura 7); a parte anterior do corpo apresenta curvatura ventral; boca circundada por três grandes lábios; ausência de cápsula bucal e bulbo posterior no esôfago. O macho apresenta asas caudais e um estreito apêndice terminal, já as fêmeas adultas os órgãos genitais estendem, anteriormente e posteriormente, até a região vulvar (TAYLOR; COOP; WALL et al., 2017b).

Figura 7 - Toxocara canis adulto. Na seta, asas cervicais

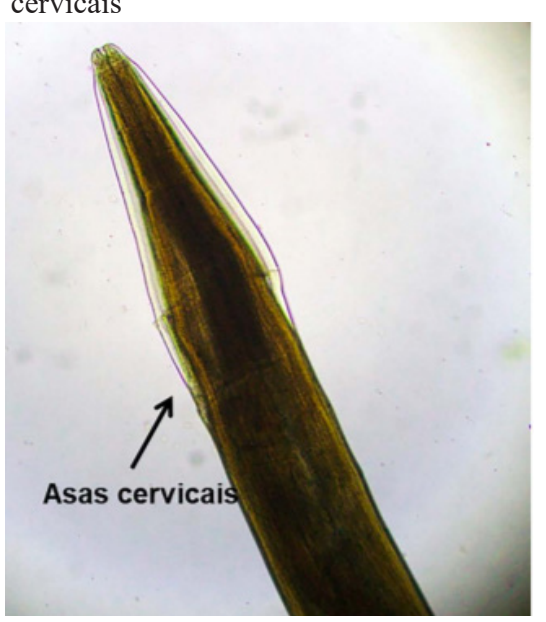

Fonte: TroCCAP (2019).

O tratamento é realizado com anti-helmínticos, havendo uma gama de agentes farmacológicos (Quadro 2), entretanto o fembendazole demonstrou-se mais eficaz e seguro para cadelas gestantes. Pomoato de pirantel também demonstra eficiência para animais jovens, especialmente com quadro de diarreia (BRESCIANI; COELHO; PAIVA, 2015; NELSON; COUTO, 2015). É preconizado que os filhotes recebam antihelmínticos na segunda semana de vida, e novamente dois a três semanas após, para eliminar infecções adquiridas na fase pré-natal. Recomenda-se uma nova administração com dois meses de idade para eliminar qualquer infecção adquirida via lactogênica ou pelo aumento na eliminação de ovos pela mãe nas semanas após o parto (TAYLOR; COOP; WALL et al., 2017b).

Pesquisas têm demonstrado a contaminação dos solos por ovos de nematódeos gastrintestinais, destacando a presença de Toxocara spp. (OLIVEIRA; SILVA; MONTEIRO, 2007; TRAVERSA et al., 2014), particularmente em regiões menos favorecidas financeiramente e onde a assistência em saúde é precária (SILVA et al., 2007). Dessa forma, o controle e a prevenção da toxocaríase merecem atenção pela alta contaminação ambiental e pelos diversos modos de transmissão, onde o solo contaminado e ou superfícies artificiais são as fontes de infecção mais importantes (NIJSSE et al., 2015).

Nesse sentido, para o controle ambiental podem ser utilizadas diferentes metodologias como: aplicação de fontes de calor com temperatura superior a $60{ }^{\circ} \mathrm{C}$ por 5 minutos (BOWMAN, 2010); exposição à luz ultravioleta; e solução aquosa iodada (OVERGAAUW; VAN KNAPEN, 2013). Entretanto, estudos têm demonstrado que a utilização de desinfetantes (Quadro 3) de rotina, com tempos de contato reduzido, não possui efeitos ovicidas satisfatórios, mas podem diminuir a aderência dos ovos às superfícies, tornando fácil a sua remoção mecânica. É recomendável também que o canil fique exposto ao sol algumas horas do dia, que seja constituído de pisos que facilitem sua higienização e que as fezes sejam removidas diariamente (FORTES, 2004). O acesso dos animais a cães errantes e outras espécies selvagens deve ser evitado (WAINDOK et al., 2021).

Quadro 3 - Principais soluções de desinfetantes comumente utilizados contra parasitos gastrintestinais primários de cães

\begin{tabular}{|l|l|}
\hline \multicolumn{1}{|c|}{ Princípio } & \multicolumn{1}{c|}{ Ação } \\
\hline Hipoclorito de sódio a 2-2,5\% & $\begin{array}{l}\text { Ancilóstomo, Toxocara } \\
\text { nematódeo. }\end{array}$ \\
\hline $\begin{array}{l}\text { Quaternários de amônio - } \\
\text { cloreto de benzalcônio 15\% }\end{array}$ & $\begin{array}{l}\text { Ancilóstomo, Toxocara } \\
\text { nematódeo. }\end{array}$ \\
\hline Borato de sódio & $\begin{array}{l}\text { Ancilóstomo, Toxocara } \\
\text { nematódeo. }\end{array}$ \\
\hline Salmoura & Ancilóstomo, Toxocara \\
\hline Álcool 70GL & Ancilóstomo, Toxocara \\
\hline Hipoclorito de sódio 25\% & Ancilóstomo, Toxocara \\
\hline Formaldeído 7,99\% & Ancilóstomo, Toxocara \\
\hline
\end{tabular}

Fonte: Ayçiçek et al., (2001); TroCCAP (2019); Ursache et al., (2019)

\subsection{Ancilostomose}

Ancilostomose é uma patologia parasitária causada por nematoides hematófagos do gênero Ancylostoma, sendo as espécies $A$. caninum e $A$. braziliense descritas frequentemente 
em cães (FORTES, 2004). A transmissão pode ocorrer pela via transmamária em filhotes recém-nascidos, por via percutânea, oral ou pela ingestão de hospedeiros paratênicos (RIBEIRO, 2004; KATAGIRI; OLIVEIRA-SEQUEIRA, 2007; BOWMAN, 2010).

Os ovos de Ancylostoma spp. eliminados nas fezes de animais parasitados, eclodem e contaminam o ambiente, ocorrendo o desenvolvimento da larva até seu terceiro estágio (L3). Essas larvas podem ser ingeridas pelo animal durante a alimentação ou lambedura, caindo no interior do trato gastrointestinal onde penetram nas glândulas gástricas ou nas glândulas de Lieberkühn do intestino delgado, em seguida, migram para o lúmen, onde atingem a maturidade e fixamse na mucosa (BOWMAN, 2010; KATAGIRI; OLIVEIRASEQUEIRA, 2007; RIBEIRO, 2004).

Quando a infecção ocorre pela via percutânea, as larvas infectantes atravessam os capilares subcutâneos ativamente, atingindo coração e pulmões, onde, neste último, perfuram os capilares dos alvéolos pulmonares, chegando à traqueia, laringe e faringe. Ao serem deglutidas caem no intestino delgado tornando adultas e dando continuidade ao ciclo (BOWMAN, 2010; CASTRO et al., 2019; FORTES, 2004).

Em cães adultos, nem todas as larvas que penetram na pele do animal fazem a migração completa até o intestino delgado; ao invés dos pulmões as larvas penetram órgãos periféricos como músculos ou parede intestinal entrando em estado de latência por longos períodos. Essas larvas L3 dormentes nos músculos podem reiniciar a migração, após meses ou anos, até o intestino do hospedeiro. Estresse, doença grave, estro, gestação, doses elevadas e/ou por tempo prolongado de corticosteroides podem predispor às reinfecções aparentes (CASTRO et al., 2019; TAYLOR; COOP; WALL et al., 2017b;).

Animais que apresentam grande carga parasitária podem desenvolver anemia microcítica hipocrômica por deficiência de ferro resultante da perda de sangue, melena, apatia, perda de peso, edemaciação e pelagem opaca. Os sinais respiratórios surgem devido a lesão causada pelas larvas nos pulmões ou pelo efeito anóxico da anemia. Outros sintomas incluem lesões de pele, dermatite e claudicação (TAYLOR; COOP; WALL, 2017b).

Em humanos, a ancilostomíase, popularmente conhecida como larva migrans cutânea (LMC), é caracterizada por uma dermatite provocada pela migração de larvas de nematódeos, no estrato epitelial da pele humana (TEIXEIRA et al., 2006).

Para a detecção dos ovos nas fezes (Figura 8) são utilizadas técnicas de flutuação simples ou centrifugo-flutuação, uma vez que os ovos são leves. Entretanto, os cães podem apresentar sinais clínicos antes que os ovos sejam detectados, sem que tenha havido conclusão do período pré-patente (BOWMAN, 2010; TAYLOR; COOP; WALL et al., 2017b).

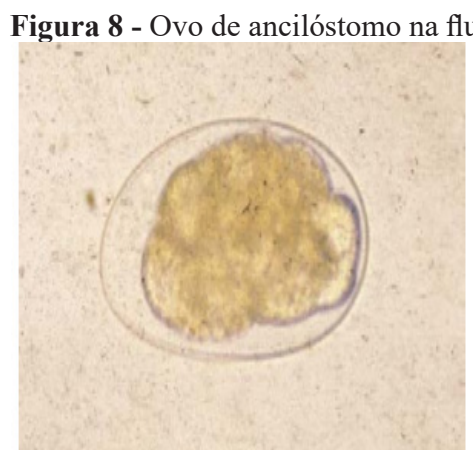

Fonte: Silveira et al. (2019).

Já os adultos são facilmente identificados com base no tamanho e pela sua conformação semelhante a um gancho; apresentam coloração cinza-avermelhados. À microscopia, apresentam extremidade anterior angular no sentido dorsal e abertura bucal direcionada no sentido anterodorsal; cápsula bucal grande com três pares de dentes marginais pontiagudos e um par de dentes ventrolaterais (Figura 9); sulco dorsal. Os machos (Figura 10) medem cerca de $12 \mathrm{~mm}$ de comprimento e possuem bolsa bem desenvolvida, já as fêmeas, 15 a $20 \mathrm{~mm}$ de comprimento (Figura 11). Os ovos possuem 34- $47 \mu \mathrm{m}$, de casca fina e lisa, com polos ligeiramente dissimilares e arredondados, paredes laterais com formato de barril (Figura 8). São constituídos por dois a oito blastômeros (TAYLOR; COOP; WALL et al., 2017b).

Figura 9 - Ancilostoma caninum adulto: cápsula bucal com três pares de dentes

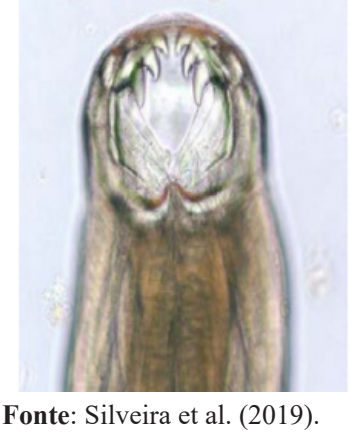

Figura 10 - Exemplar adulto de Ancilostoma caninum: vista anterior e posterior, respectivamente,.de um macho
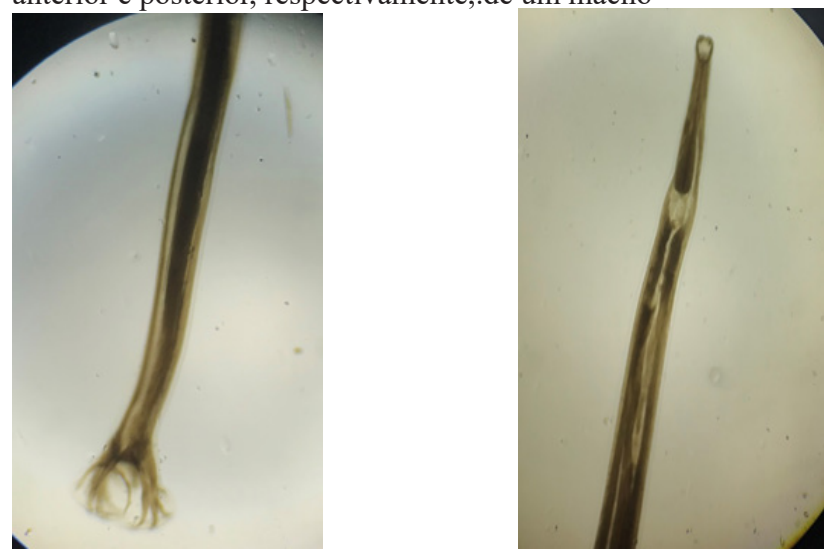

Fonte: Os autores. 
Figura 11 - Exemplar adultosde Ancilostoma caninum: vista anterior e posterior, respectivamente, de uma fêmea
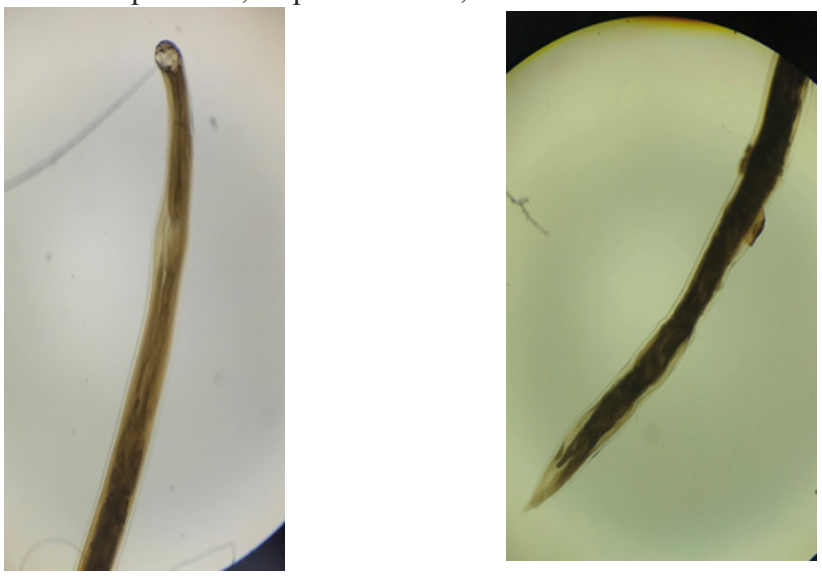

Fonte: Os autores.

Para o tratamento da ancilostomose são indicados anti-helmínticos à base de pirantel e praziquantel (Quadro 2). Entretanto, segundo Castro et al. (2019), o aumento drástico na casuística de infecções recorrentes / persistentes por ancilostomídeos caninos nos últimos anos sugere uma resistência anti-helmíntica. Ainda, em casos severos, é aconselhável terapia suporte com a suplementação de ferro, vitamina B12, o fornecimento de uma dieta rica em proteína e, se necessário, transfusão sanguínea (TAYLOR; COOP; WALL et al., 2017b).

Assim como já descrito para T. canis, o controle de Ancylostoma spp. requer ações de controle ambiental (VERONESI; FOCACCIA, 2004; BOWMAN, 2010).

\subsection{Dipilidiose canina}

Dipylidium caninum é um cestódeo comumente reportado parasitando cães (PEREIRA et al., 2017), sendo transmitidos pela ingestão de artrópode tais como as pulgas Ctenocephalides felis e Xenopsylla cheopis (PUGH, 1987) e piolhos Trichodectes canis e Felicola subrostratus (TAYLOR; COOP; WALL et al., 2017b; BEUGNET et al., 2018).

Possui uma distribuição cosmopolita e é de ocorrência mais comum em cães, especialmente em animais negligenciados, embora também ocorra em animais bem tratados (TAYLOR; COOP; WALL et al., 2017b).

Estudos mais recentes, sugerem a existência de dois genótipos distintos de D. caninum envolvidos na transmissão por de pulgas C.felis (BEUGNET et al., 2018). Ainda segundo o autor, o genótipo canino ocorre com maior frequência em cães, enquanto o genótipo felino ocorre com maior frequência em gatos.

Os adultos de D. caninum (Figura 12) parasitam principalmente cães e gatos, e embora raramente, parasitam humanos, demonstrando sua importância como zoonose (MEHLHORN, 2021). Possuem de 20 a $80 \mathrm{~cm}$ de comprimento e 3 a 4 mm de largura; escólex com quatro ventosas (TAYLOR; COOP; WALL et al., 2017b) um rostelo protrátil com três a cinco fileiras de pequenos ganchos em formato de espinhos de rosa (TAYLOR; COOP; WALL et al., 2017b); seu corpo, por sua vez, é segmentado, sendo constituído por várias proglotes facilmente identificadas, de formato alongado, se assemelhando a grãos de arroz ou sementes de pepino, sendo eliminadas nas fezes. Cada proglote (Figura 13) apresenta dois conjuntos de órgãos genitais com uma abertura de poro em cada margem (BOWMAN, 2014; TAYLOR; COOP; WALL et al., 2017b; MEHLHORN, 2021), sendo móveis quando recém-eliminadas, podendo ser confundidas com vermes ou larvas de mosca (McCONNAUGHEY, 2007).

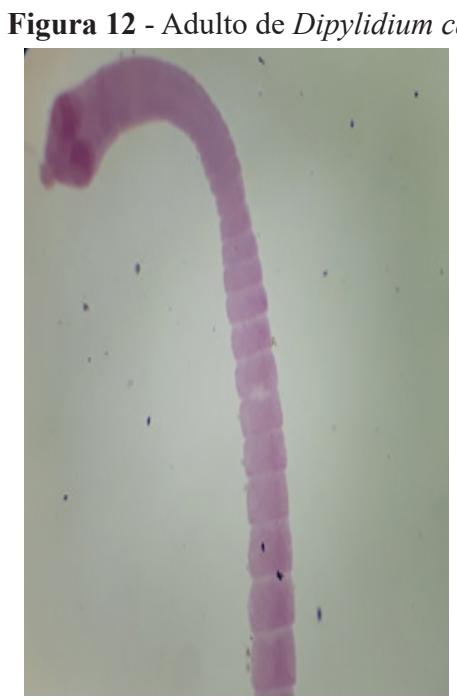

Fonte: Os autores.

Figura 13 - Proglotes grávidas de D. caninum

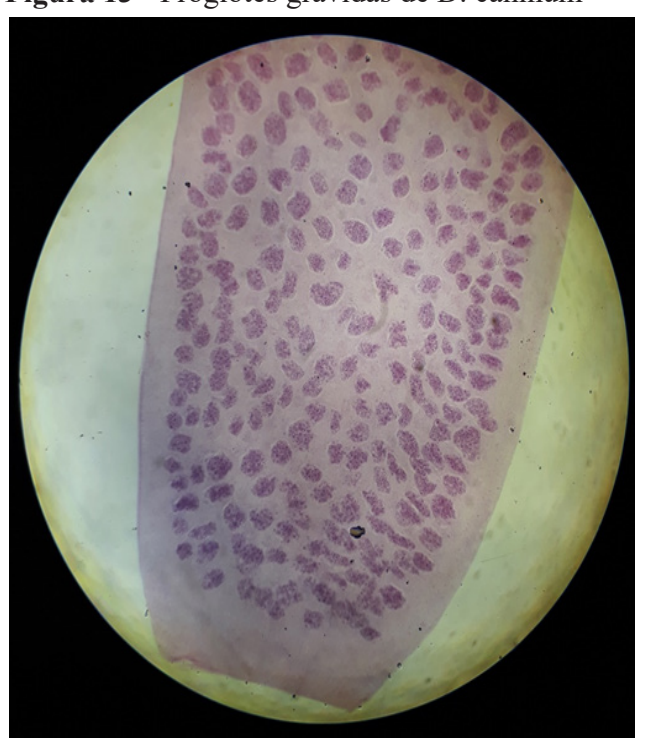

Fonte: Os autores.

Já os ovos são expelidos pelo hospedeiro definitivo dentro de uma cápsula ovarígena (Figura 14), de aproximadamente 120 a $200 \mu \mathrm{m}$, que pode conter até 30 ovos. Cada ovo mede de 25 a $50 \mu \mathrm{m}$, possuem coloração castanho-amarelada, sendo quase subesféricos, e contém em seu interior um embrião hexacanto (BOWMAN, 2014; MEHLHORN, 2021). 
Figura 14 - Ovos de D. caninum envoltos pela cápsula ovígera

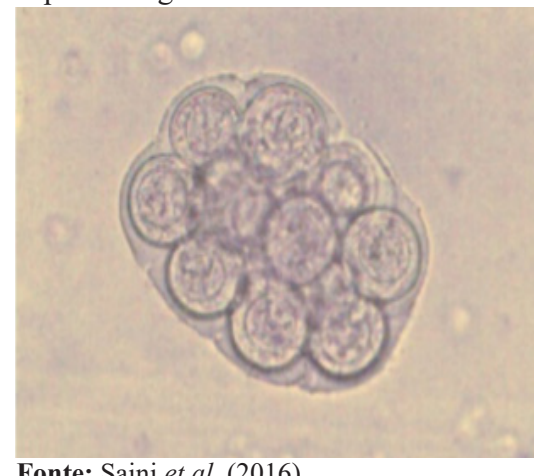

Fonte: Saini et al. (2016).

O ciclo biológico e de transmissão envolve a excreção das proglotes grávidas, que são capazes de se mover vários centímetros por hora (McCONNAUGHEY, 2007), que no ambiente, se desintegram e liberam as cápsulas ovígeras com os ovos embrionados (TAYLOR; COOP; WALL et al., 2017b). As larvas de malófagos ou pulgas adquirem o cestódeo ao ingerir esses pacotes de ovos, que no que lhe concerne, eclodem liberando as oncosferas que passam para a cavidade corporal do inseto, onde se desenvolvem em cisticercoides (McCONNAUGHEY, 2007; TAYLOR; COOP; TAYLOR; COOP; WALL et al., 2017b; MEHLHORN, 2021). Todos os estágios de piolhos mordedores podem ingerir oncosferas, já nas pulgas a infecção somente ocorre durante o estágio larvário, dado que possuem estruturas bucais mastigadoras (TAYLOR; COOP; WALL et al., 2017b).

O hospedeiro definitivo, por sua vez, se infecta após a ingestão de pulga ou de piolho contendo o cisticercoide, durante a lambedura, dando continuidade ao novo ciclo (McCONNAUGHEY, 2007; TAYLOR; COOP; WALL et al., 2017b; MEHLHORN, 2021). Pode ocorrer tanto a reinfecção do mesmo cão, bem como a transmissão para outros hospedeiros definitivos, pela ingestão das pulgas ou os malófagos infectados (MEHLHORN, 2021). Os primeiros segmentos grávidos podem ser eliminados cerca de três semanas, caracterizado como desenvolvimento da patência (TAYLOR; COOP; WALL et al., 2017b).

As formas adultas não são patogênicas, sendo tolerado muitas centenas de parasitos sem sinais clínicos. Entretanto, o animal pode manifestar prurido anal, pela movimentação ativa das proglotes, por meio da observação de lambedura excessiva da região perineal (TAYLOR; COOP; WALL et al., 2017b). A presença das proglotes na região perianal e perineal, ou, ainda, nas fezes também pode ser macroscopicamente observada (SAINI et al., 2016). Em grandes infecções pode ser observada diarreia, perda de peso, anorexia, má desenvolvimento nos animais jovens (WANI et al, 2015; SAINI et al., 2016) e até mesmo, embora raro, intussuscepção intestinal aguda (RIMAL et al. (2020). Ainda, anemia e patologias dermatológicas, como a dermatite alérgica à picada de ectoparasitas (DAPE) podem estar associadas, em associada ao parasitismo por seus vetores (FARKAS et al., 2009).
Em humanos, infecções por D. caninum ocorrem ocasionalmente, principalmente em crianças que adquirem a infecção pela ingestão de hospedeiros intermediários, como pulgas (CHELLADURAI et al., 2018). É uma doença associada com o contato próximo com animais de estimação infectados, tendo distribuição mundial e geralmente assintomáticas, entretanto pode causar alterações de apetite, diarreia, agitação, dor abdominal, obstipação, prurido e dor anal (CABELLO et al., 2011; JIANG et al. 2017).

O diagnóstico para D. caninum pode ser realizado através do histórico como ausência de controle de pulgas e vermifugação com praziquantel, assim como sinais clínicos e detecção de proglotes nas fezes, na pelagem e no ambiente (TroCCAP, 2019) ou ao redor do ânus (SAINI et al., 2016; TAYLOR; COOP; WALL et al., 2017b; TroCCAP, 2019). No exame fecal direto observa-se a presença de segmentos grávidos com formas alongadas, que podem ser diferenciadas de Taenia spp. pela forma e presença de dois poros genitais bilateralmente simétricos localizados no meio do segmento (TroCCAP, 2019).). Ocasionalmente, cápsulas de ovos são detectadas por métodos de flutuação fecal, mas esse método não é sensível, visto que a eliminação de ovos livres nas fezes é um evento raro (TroCCAP, 2019).

$\mathrm{Na}$ dipilidiose canina, preconiza-se o tratamento conjuntamente ao controle, objetivando tanto a eliminação do $D$. canino como de seus hospedeiros intermediários (BEUGNET et al., 2013; TAYLOR; COOP; WALL et al., 2017b).

Praziquantel é o medicamento de escolha para infecções por cestódeos, (ALMEIDA et al., 2011; TAYLOR; COOP; WALL et al., 2017b; CHELLADURAI et al., 2018). O epsiprantel, uma isoquinolona intimamente relacionada ao praziquantel, já foi referida no tratamento (MANGER; BREWER, 1989). Entretanto, Chelladurai et al. (2018) relatam a resistência de $D$. caninum ao praziquantel, mesmo utilizando doses mais altas e tratamento prolongado. Ainda, podem ocorrer reinfestações principalmente em decorrência de administração na frequência inadequada, bem como a ausência de retratamento necessário, uma vez que o praziquantel não possui efeito residual (FOURIE et al., 2013).

Atualmente, várias bases farmacológicas pulicidas, tanto na forma oral como tópica, e com ação repelente, têm sido descritas como eficientes no controle da transmissão de $D$. caninum (BLAGBURN; DRYDEN, 2009; FOURIE et al., 2013; GOPINATH et al., 2018) Ainda nesse sentido, Fourie et al. (2013) menciona que a utilização de coleiras antipulgas pode ser uma medida eficaz no controle de $D$. caninum, principalmente em pulgas infectadas com metacestódeos, reduzindo, inclusive, a probabilidade de transmissão para humanos. É importante sempre a associação ao controle ambiental (KATAGIRI; OLIVEIRA-SEQUEIRA, 2008). Dessa forma, os locais onde habitam e repousam o animal, devem receber controle mecânico e aplicação de inseticidas para a eliminação dos estágios imaturos das pulgas, sendo a 
população deste estágio mais numerosa que as formas adultas, que se encontram na forma parasitária no animal (TAYLOR; COOP; WALL et al., 2017b).

\section{Conclusão}

Conhecer o ciclo biológico e as formas de transmissão de cada parasito é imprescindível para compreender suas formas de disseminação, as técnicas diagnósticas apropriadas e a prevenção das enfermidades.

Atenção especial deve ser dada na prescrição de fármacos, seja de forma preventiva como curativa, objetivando o uso racional de modo a coibir parasitoses resistentes. Adicionalmente às estratégias farmacológicas, deve ser implementado o controle ambiental para o êxito do controle das endoparasitores.

Ainda, devido o patencial zoonótico dos diversos parasitas de animais, o conceito de One Health deve estar, a cada dia, mais inserido na sociedade e principalmente entre os médicos veterinários, sendo estes profissionais importantes no processo de educação em saúde.

\section{Referências}

ADAM, R.D. Biology of Giardia lamblia. Microb. Rev., v.14, n.3, p.447-475, 2001

ADOLPH, C. Coccidia. In: BRUYETTE, D.S. et al. Clinical small animal internal Medicine. Wiley BlackWell, 2020. p.10231027. doi: 10.1002/9781119501237

ALMEIDA, M.A.O. et al. Agentes antinematódeos. In: SPINOSA H. S. et al. Farmacologia aplicada à medicina veterinária. Rio de Janeiro: Guanabara Koogan, 2011. p.860-880.

ALVES, O.F.; GOMES, A.G; SILVA, A.C. Ocorrência de enteroparasitos em cães do município de Goiânia, Goiás: comparação de técnicas de diagnóstico. Ciênc. Anim. Bras., v.6, n.2, p.127-133, 2005.

ANDERSON, K.A. et al. Impact of Giardia vaccination on asymptomatic Giardia infections in dogs at a research facility. Can. Vet. J., v.45, n.11, p.924-930, 2004.

AYÇIÇEK H, et al. Efficacy of some disinfectants on embryonated eggs of toxocara canis. Turk. J. Med.Sci. v. 31, n. 1, p. 35-39, 2001.

BALLWEBER, L.R. et al. Giardiasis in dogs and cats: update on epidemiology and public health significance. Trends Parasitol., v.26, n.4, p.180-189, 2010. doi: 10.1016/j.pt.2010.02.005.

BARUTZKI, D. et al. Eficácia de Pamoato de Pirantel, Febantel e Praziquantel contra Giardia em cães Naturalmente Contaminados. Giardia: Informativo Técnico, p.5-7, 2000.

BEUGNET, F. et al. Preventive efficacy of Frontline ${ }^{\circledR}$ Combo and Certifect ${ }^{\circledR}$ against Dipylidium caninum infestation of cats and dogs using a natural flea (Ctenocephalides felis) infestation model. Parasite, v.20, p.7, 2013. doi:10.1051/parasite/2013006

BEUGNET, F. et al. Analysis of Dipylidium caninum tapeworms from dogs and cats, or their respective fleas - Part 2. Distinct canine and feline host association with two different Dipylidium caninum genotypes. Partie 2. Parasite v.25, n.31, 2018. doi: https://doi.org/10.1051/parasite/2018029

BICA V. C.; DILlenburG A. F.; TASCA T. Diagnóstico laboratorial da giardiose humana: comparação entre as técnicas de sedimentação espontânea em água e de centrífugo-flutuação em solução de sulfato de zinco. HCPA, v.31, n.1, p.39-45, 2011.

BOWMAN, D.D. Helmintos In.: Bowman, D.D. et al. Georgi Parasitologia Veterinaria. Rio de Janeiro: Elsevier, 2010. p.153155.

BOWMAN, D.D. Helminths In: BOWMAN, D.D. et al. Georgis' Parasitology for Veterinarians. Elsevier, 2014. p.122-227.

BOWMAN, D. D. The Challenges with Canine Giardia. In: STRUB, E.C.; MEHLHORN, H. Dog parasites endangering human health. v. 13. Springer, Cham. 2021. p. 45-71. doi: 10.1007/978-3-030-53230-7 4

BRESCIANI, K.D.S.; COELHO, W.M.D.; PAIVA, F. Isosporose. In: JERICÓ, M.M.; KOGIKA, M.M.; ANDRADE NETO, J.P. (Org.). Tratado de medicina interna de cães e gatos. Rio de Janeiro: Roca, 2015. p.695-696.

BURET, A.G. Pathophysiology of enteric infections with Giardia duodenalis. Parasite, v.15, n.15, p. 261-265, 2008. doi: 10.1051/ parasite/2008153261

BURET, A. G. et al. Giardia duodenalis: New Research Developments in Pathophysiology, Pathogenesis, and Virulence Factors. Curr Trop. Med. Rep., v.2, n.3, p.110-118, 2015. doi: 10.1007/s40475-015-0049-8.

CABELLO, R. R. et al. Dipylidium caninum infection. BMJ Case Rep, 2011. doi: 10.1136/bcr.07.2011.4510

CAPUANO, D.M.; DE MELO ROCHA, G. Ocorrência de parasitas com potencial zoonótico em fezes de cães coletadas em áreas públicas do município de Ribeirão Preto, SP, Brasil. Rev. Bras. Epidemiol., v.9, n.1, p. 81-86, 2006. doi: 10.1590/S1415790X2006000100010.

CARLIN, E. P.; TYUNGU, D. L. Toxocara: Protecting pets and improving the lives of people. Adv. Parasitol., v.109, p.3-16, 2020. doi: 10.1016/bs.apar.2020.01.001.

CASTRO, P. D. J. et al. Multiple drug resistance in the canine hookworm Ancylostoma

caninum: An emerging threat? Parasit Vectors, v. 12, n. 1, p. 576, 2019. doi: 10.1186/s13071-019-3828-6.

CHELLADURAI, J.J. et al. Praziquantel Resistance in the Zoonotic Cestode Dipylidium caninum. Am. J. Trop. Med. Hyg., v. 99 , n.5, p. 1201-1205, 2018. doi:10.4269/ajtmh.18-0533

DAY, M.J. et al. Diretrizes para a Vacinação de Cães e Gatos. J. Small Anim. Pract., v. 57, 2016. Disponível em: https:// wsava.org/wp-content/uploads/2020/01/WSAVA-vaccinationguidelines-2015-Portuguese.pdf. Acesso em: 20 out. 2021.

DOS SANTOS REGINALDO, G.M. et al. Canine isosporosis: a neonatal clinical approach. Semina Cienc. Agra., v.40, n.6, p.37973804, 2019. doi: 10.5433/1679-0359.2019v40n6Supl3p3797.

DUBEY, J. P. Re-evaluation of merogony of a Cystoisospora ohioensis- like coccidian and its distinction from gametogony in the intestine of a naturally infected dog. Parasitology, v.146, n.6, p.740-745, 2019. doi: 10.1017/s0031182018002202.

ELÍGIO-GARCÍA, L.; CORTÉS-CAMPOS, A.; JIMÉNEZCARDOSO, E. Classification of Giardia intestinalis isolates by multiple polymerase chain reaction (multiplex). Parasitol Res, v.103, n.4, p.797-800, 2008. doi: 10.1007/s00436-008-1042-0

ELSEMORE, D.A. et al. Enzyme-linked immunosorbent assays for coproantigen detection of Ancylostoma caninum and Toxocara canis in dogs and Toxocara cati in cats. J. Vet. Diagn. Invest., v.29, n.5, p.645-653, 2017. doi:10.1177/1040638717706098.

ESCCAP - European Scientific Counsel Companion Animal 
Parasites. Control of intestinal protozoa in dogs and cats. ESCCAP Guidelines. n.6. First Edition, p.1-24. Worcestershire, UK: ESCCAP, 2011.

FANTINATTI, M. et al. Epidemiology of giardia duodenalis assemblages in brazil: There is still a long way to go. Mem. Inst. Oswaldo Cruz, v.115, n.11, p.1-12, 2020. doi: 10.1590/007402760200431

FARKAS, R. et al. Prevalence of flea infestation in dogs and cats in Hungary combined with a survey of owner awareness. Med. Vet. Entomol, v.23, n.3, p.187-194, 2009. doi:10.1111/j.13652915.2009.00798.x

FERREIRA, C.G.T.; BEZERRA, A.C.D.S.; AHID, S.M.M. Endoparasitas em cães (Canis familiaris L.) em Apodi, Rio Grande do Norte, Brasil. PUBVET, v. 4, n.20, 2010.

FORTES, E. Parasitologia Veterinária. São Paulo: Ícone, 2004.

FOURIE, J.J. Prophylactic treatment of flea-infested dogs with an imidacloprid / flumethrin collar (Seresto ${ }^{\circledR}$, Bayer) to preempt infection with Dipylidium caninum. Parasitol. Res., v.112, p.3346, 2013. doi: 10.1007/s00436-013-3279-5

FUNADA, M.R. et al. Freqüência de parasitos gastrintestinais em cães e gatos atendidos em hospital-escola veterinário da cidade de São Paulo. Arq. Bras. Med. Vet., v.59, n.5, p.1338-1340, 2007. doi: 10.1590/S0102-09352007000500038.

GENNARI S.M.; SOUZA S. L. P. Giardíase. Bol. Tec. FortDodge: Saúde Animal, p.1-13, 2003.

GEURDEN, T. et al. A Bayesian evaluation of three diagnostic assays for the detection of Giardia duodenalis in symptomatic and asymptomatic dogs. Vet. Parasitol. v.157, n.1/2, p.14-20, 2008. doi:10.1016/j.vetpar.2008.07.002.

GOPINATH, D. et al. Topical or oral fluralaner efficacy againstflea (Ctenocephalides felis) transmission ofDipylidium caninuminfection to dogs. Parasites \& Vectors., v.11, n.557, 2018. doi: 10.1186/s13071-018-3140-x

JIANG, P. et al. A Human Case of Zoonotic Dog Tapeworm, Dipylidium caninum (Eucestoda: Dilepidiidae), in China. Korean J Parasitol. v. 55, n.1, p.61-64, 2017. doi: 10.3347/kjp.2017.55.1.61

JOACHIM, A. et al. W A A V P guideline for evaluating the efficacy of anticoccidials in mammals (pigs, dogs, cattle, sheep). Vet. Parasitol., v.253, p.102-119, 2018. doi: 10.1016/j. vetpar.2018.02.029.

KATAGIRI, S.; OLIVEIRA-SEQUEIRA, T.C.G. Zoonoses causadas por parasitas intestinais de cães e o problema do diagnóstico. Arq. Inst. Biol., v.74, n.2, p.175-184, 2007.

KRAFT, M.R. et al. Giardia's Epithelial Cell Interaction In Vitro: Mimicking Asymptomatic Infection? Front. Cell. Infect. Microbiol. v.7, p.421, 2017. doi: 10.3389/fcimb.2017.00421

LALlO, M. A., RODRIGUES, L. C. S.; BONDAN, D. F. Giardíase em cães e gatos: revisão. Rev. Clín. Vet., n.43, p.40-44, 2003.

LALLO, M.A.; BONDAN, E.F. Giardíase. In: MEGID, J.; RIBEIRO, M.G.; PAES, A.C. Doenças infecciosas em animais de produção e companhia. Rio de Janeiro: Roca, 2016. p.997-1003.

LEAL, P.D.S et al. Choleimeria rochalimai (Apicomplexa: Eimeriidae) a pseudoparasite of the dog: case report. Rev. Bras. Med. Vet., v.37 (Supl. 3), p.14-16, 2016

LUND, E. et al. (2010) Assessment of risk for diarrhea in young dogs after Giardia vaccine administration. J. Vet. Intern. Med., v.24, p.660-795, 2010. doi:10.1111/j.1939-1676.2010.0521.x
MAGNAVAL, J. F. et al. Highlights of human toxocariasis. Korean J. Parasitol., v.39, n.1, 2001.

MANGER, B.R.; BREWER, M.D. Epsiprantel, a new tapeworm remedy. Preliminary efficacy studies in dogs and cats. Ir. Vet. J., v.145, n.4, p.384-388, 1989. doi: 10.1016/00071935(89)90038-9

MANKO-PRYKHODA, A. et al. Giardia spp. promote the production of antimicrobial peptides and attenuate disease severity induced by attaching and effacing enteropathogens via the induction of the NLRP3 inflammasome. Int. J. Parasitol. v.50, n.4, p.263-275, 2020. doi:10.1016/j.ijpara.2019.12.011

McCONNAUGHEY, M. Life Cycle of Parasites. In.: ENNA, S.J.; BYLUND, D.B. The Comprehensive Pharmacology Reference. Elsevier, 2007, p.1-15. doi:10.1016/B978-008055232-3.60232-6.

MEHLHORN H. Dipylidium caninum. In: STRUBE C., MEHLHORN H. Dog Parasites Endangering Human Health. Parasitol. Res. Monog., v.13, p.141-147, 2021. doi: 10.1007/978-3-030-53230-7 8

MERIGUETI, Y. F. F. B. et al. Protective and risk factors associated with the presence of Toxocara spp. eggs in dog hair. Vet. Parasitol, v.244, p.39-43, 2017. doi:10.1016/j.vetpar.2017.07.020.

MORON-SOTO, M. et al. Efficacy of nitazoxanide to treat natural Giardia infections in dogs. Parasites Vectors, v.10, n.1, p.52, 2017. doi:10.1186/s13071-017-1998-7

NELSON, R.W.; COUTO, C.G. Enfermidades intestinais. In.: BUNCH, S.E. et al., Medicina interna de pequenos animais. Rio de janeiro: Elsevier, 2015, p.468-505.

NIJSSE, R. et al. Coprophagy in dogs interferes in the diagnosis of parasitic infections by faecal examination. Vet. Parasitol, v.204, n.3/4, p. 304-309, 2014. doi: 10.1016/j.vetpar.2014.05.019.

NIJSSE, R. et al. Toxocara canis em cães domésticos: prevalência, fatores de risco e atitude dos proprietários em relação à vermifugação. Parasitol. Res., v.114, n.2, p.561-569, 2015. doi: 10.1007 / s00436-014-4218-9 .

OLIVEIRA, C.B.; SILVA, A.S.; MONTEIRO, S.G. Ocorrência de parasitas em solos de praças infantis nas creches municipais de Santa Maria - RS, Brasil. Rev. FZVA, v.14, p.174-179, 2007.

OLSON, M.E.; BURET, A.G. Giardia and Giardiasis In.: SAUEL,WM; PYBUS, MJ; KOCAN, AA; (2001). Parasitic diseases of wild mammals. Iowa: Iowa State University Press, 2001. p.399-415.

OVERGAAUW, P. A. M.; VAN KNAPEN, F. Veterinary and public health aspects of Toxocara spp. Vet. Parasitol, v. 193, n. 4, p.398-403, 2013. doi: 10.1016/j.vetpar.2012.12.035.

PAYNE P. A. et al. Efficacy of a combination febantelpraziquantelpyrantel product, with or without vaccination with a commercial Giardia vaccine, for treatment of dogs with naturally occurring giardiasis. J. Am. Vet. Med. Assoc., n.220, p.330-333, 2002. doi: 10.2460/javma.2002.220.330.

PEREIRA, P.F. et al. Gastrointestinal parasites in stray and shelter cats in the municipality of Rio de Janeiro, Brazil. Braz. J. Vet. Parasitol., v.26, n.3, p.383-388, 2017. doi: 10.1590/S198429612017024

PINTO FERREIRA, F. et al. Frequência de parasitas gastrointestinais em cães e gatos do município de Londrina, PR, com enfoque em saúde pública Semina: Ciênc. Agrar., v.34, n.2, p.3851-3858, 2013.

PUGH, R. E. Effects on the development of Dipylidium caninum and on the host reaction to this parasite in the adult flea (Ctenocephalides felis felis). Parasitol. Res. v.73, n.2, p.171-177, 1987. doi: 10.1007/BF00536475 
RAMOS, R.A.N et al. Isosporose. In: MEGID, J.; RIBEIRO, M.G.; PAES, A.C. Doenças Infecciosas em animais de produção e companhia. Rio de Janeiro: Roca, 2016. p.1009-1012,

RIBEIRO, V. M. Controle de helmintos de cães e gatos. Rev. Bras. Parasitol. Vet, v.13, p.88-95, 2004.

RODRIGUES, A.N.; MENEZES, R.C. A. A. Infecção natural de cães por espécies do gênero Cystoisospora (Apicomplexa: Cystoisosporinae) em dois sistemas de criação. Clínica Veterinária, n. 42, p. 24-30, 2003.

RYAN, U.; CACCIÒ, S. M. Zoonotic potential of Giardia. Int. J. Parasitol. v.43, n. 12-13, p. 943-956, 2013. doi: 10.1016/j. ijpara.2013.06.001.

SAINI, V.K. et al. Diagnosis and therapeutic management of Dipylidium caninum in dogs: a case report. J. Parasit Dis. v.40, n. jan, p.1426-1428, 2016. doi: 10.1007/s12639-0150706-9

SCHNIEDER, T.; LAABS, E. M.; WELZ, C. Larval development of Toxocara canis in dogs. Vet. Parasitol., v.175, n. 3-4, p. $193-$ 206, 2011.

SILVA, J. et al. Spatial distribution and enteroparasite contamination in peridomiciliar soil and water in the Apucaraninha Indigenous Land, southern Brazil. Braz. J. Microbiol. v.38, n.2, p.337-345, 2007. doi: 10.1007/s10661-016-5216-4.

SILVA, J.C.S. et al. Endoparasitas em cães e gatos diagnosticados em São Luís - Maranhão. PUBVET v.11, n.6, p.587-595, jun., 2017.

SILVEIRA, J. A. G. et al. Atlas de Parasitologia Veterinária. Cad. Técnicos Vet. Zootec., n.92, 2019.

SOUZA, S.L.P. Giardíase. In.: JERICÓ, M.; KOGIKA, M.; DE ANDRADE NETO, J. Tratado de medicina interna de cães e gatos. Rio de Janeiro: Roca, 2015, p. 2121 - 2132.

TANGTRONGSUP, S.; SCORZA, V. Update on the diagnosis and management of Giardia spp infections in dogs and cats. Top. Companion Anim. Med., v.25, n.3, p.155-162, 2010. doi: 10.1053/j.tcam.2010.07.003.

TAYLOR, M.A.; COOP, R.L.; WALL, R.L. Protozoologia Veterinária. In: FAGLIARI J.J.; ROCHA T.G. Parasitologia veterinária. Rio de Janeiro: Guanabara Koogan; 2017a. p.479665.

TAYLOR, M.A.; COOP, R.L.; WALL, R.L. Helmintologia
Veterinária. In: FAGLIARI, J.J.; ROCHA, T.G. Parasitologia veterinária. Rio de Janeiro: Guanabara Koogan; 2017b. p.65-478.

TESSEROLLI, G.L.; FAYZANO, L.; AGOTTANI, J.V.B. Ocorrência de parasitas gastrointestinais em fezes de cães e gatos, Curitiba - PR. Rev. Acadêm., v.3, n.4, p.31-34, 2005. doi: 10.7213/cienciaanimal.v3i4.9207.

TEIXEIRA, C. R. et al. Frequency and risk factors for toxocariasis in children from a pediatric outpatient center in Southeastern Brazil. Rev. Inst. Med. Trop., v.48, n.5, p.251-255, 2006. doi|: 10.1590/S0036-46652006000500003.

TRAVERSA, D. et al. Environmental contamination by canine geohelminths Parasit. Vectors. v. 7, n. 1, p. 1-9, 2014. doi:10.1186/1756-3305-7-67.

TROPICAL COUNCIL FOR COMPANION ANIMAL PARASITES, 2019. Diretrizes para o diagnóstico, tratamento e controle de endoparasitas caninos nos trópicos. Disponível em: https://www.troccap.com/2017press/wp-content / uploads / 2019/05 / TroCCAP_Canine_Endo_Guidelines_English_Ver2. pdf

URSACHE, A.L. et al. Is routine disinfection effincient in preventing contamination with Toxocara canis eggs? J Helmintol. v. 94, e60, p. 1-4, 2019. doi: 10.1017/S0022149X1900052X.

VASCONCELOS, M.C.; BARROS, J.S.L.; OLIVEIRA, C.S. Parasitas gastrointestinais em cães institucionalizados no Rio de Janeiro, RJ. Rev. Saúde Pública, v.40, n.2, p.321-323, 2006.

VERONESI, R., FOCACCIA R. Tratado de infectologia. São Paulo: Atheneu: São Paulo, 2004. p.1339-1344.

VIDAL, A.M.B.; CATAPANI, W.R. Enzyme-linked immunosorbent assay (ELISA) immunoassaying versus microscopy: Advantages and drawbacks for diagnosing giardiasis. Sao Paulo Med. J., v. 123, n. 6, p. 282-285, 2005. doi: 10.1590/ S1516-31802005000600006

WAINDOK, P. et al. The Zoonotic Dog Roundworm Toxocara canis, a Worldwide Burden of Public Health. [S. 1.]: Springer, Cham, 2021. p.5-26.

WANI, Z. A. et al. Dipylidium caninum infection in dogs infested with fleas. J. Parasit Dis., v. 39, n. 1, p. 73-75, 2015. doi: 10.1007/ s12639-013-0281-x

VATNIKOV, Y.U. et al. Pathological influence of concomitant infestation of Cystoisospora SP. and Giardia SP. in dogs. EurAsian J. BioScie., v.14, p.4171-4178, 2020. 